J. Product. \& Dev., 14(2): 313 - 328 (2009)

\title{
EFFECT OF SUCROSE AND MS-SALT STRENGTH CONCENTRATIONS ON THE DEVELOPMENT OF DATE PALM PLANTLETS DURING ROOTING STAGE
}

\author{
M. A. EL-Kahteeb*, Azza M. S. Arafa*, A. A. EL-Banna** and Eman M. \\ Zayed $* *$ \\ * Department of Ornamental Horticulture, Faculty of Agriculture, Cairo \\ University, Giza, Egypt. \\ ** Central Lab. For Date Palm Researches and Development, ARC. Egypt.
}

\begin{abstract}
Date palm dry cultivars (Bartamuda and Sakkoty) plantlets resulted from somatic embryogenesis were transferred to different treatment for rooting stage to encourage root growth and then production a suitable plantlet for acclimatization stage. plantlets were cultured in sucrose at $(0.0,10$ and $20 \mathrm{~g} / \mathrm{L})$ combined with MS-salt strength at (1/2, 1/4, 1/8 and 1/16 MS) in addition to NAA at $0.1 \mathrm{mg} / \mathrm{L}$ to liquid media without charcoal, the highest mean value of secondary root number and secondary root length was obtained by using free sucrose followed by $10 \mathrm{~g} /$ $L$ sucrose, on the other hand no signification difference between 10 and 20 $g / L$ sucrose on a highest value of root number. MS-salt strength affect significantly on plant height, 1/2 MS achieved a highest significant plant height, no significant difference were observed between 1/2, 1/4 and 1/16 $M S$ on a highest value of root number. The combined effect between sucrose concentration and MS salt strength indicated that the best medium to stimulate the growth and development of adventitious roots of date palm plantlets which contained the 1/4 MS salt strength supplemented with $20 \mathrm{~g} /$ $L$ sucrose. Sakkoty cv. produced the highest significant value of plant height, leave number, root number and root length compared with Bartamuda cv.
\end{abstract}

Key words: Salt strength, sucrose, in vitro, tissue culture, date palm.

\section{INTRODUCTION}

Date palm (Phoenix dactylifera L.) belongs to family Palmaceae (Arecaceae). The multiplication of date palm, a dioeciously monocotyledonous species, was traditionally achieved by seeds and by off-shoots. However, these methods are not sufficient to rehabilitate the date palm groves and can inadvertently spread diseases (El-Hadrami et al, 1998). Tissue culture micropropagation has been employed to aid in the colonial propagation of 
numerous plant species (DE-Fossard, 1976). Propagation of palms in vitro has been achieved through the initiation of embryogenic callus which subsequently gives rise to asexual plantlets (Nwankwo and Krikorian, 1983). The negative effects of high sucrose concentration on root formation by the transformation of added sugars to soluble and storage forms (Haissing, 1984).

Lowering the microelements concentration in the applied basal media of fruit trees usually results in an increase in rooting (Newmeth, 1986). This study was carried out to determine the best sucrose concentrations and medium strength on the rooting stage of date palm dry cultivars (Sakkoty and Bartamuda).

\section{MATERIALS AND METHODS}

This study was carried out in the Central Laboratory of Development of Date palm Research at Giza, Egypt during the period from 2003-2008.

\section{Young date palm plants were established as follows:}

Adventitious roots, fibrous sheath and leaves of selected young offshoots were removed acropetally with the help of pruning scissors and serrated knife. Under aseptic condition, outer leaves were removed to obtain a terminal portion of the shoot, which was $1-2 \mathrm{~cm}$ in length and about $0.5-1.0 \mathrm{~cm}$ in width.

Date palm explants were surface sterilized by $0.3 \% \mathrm{Hg} \mathrm{Cl}_{2}$ for 5 minutes and dipping the explants in $1.0 \% \mathrm{NaOCl}$ solution for 5 seconds before culture. Shoot tip explants and MS medium supplemented with $100 \mathrm{mg} / \mathrm{L} \mathrm{2}$, 4dichlorophenoxyacetic acid (2.4-D) $+3 \mathrm{mg} / \mathrm{L}$ 2-isopenteny1 adenine (2ip) were used to produce embryogenic callus. Embryos were obtained by using MS nutrient medium containing $0.1 \mathrm{mg} / \mathrm{L} \mathrm{NAA}+0.05 \mathrm{mg} / \mathrm{L} \mathrm{BA}+100 \mathrm{mg} / \mathrm{L}$ activated charcoal. Repeated subcultures of individual embryos which gave plantlets of date palm cultivars were used as explants.

The basic media used in the experiments were that of Murashige and Skoog (MS. 1962) at different salt concentrations, supplemented with $0.1 \mathrm{mg} / \mathrm{L}$ naphthaleneacetic acid (NAA) without charcoal ( Tisserat, 1984). The $\mathrm{pH}$ of the media was adjusted to $5.0 \pm 0.1$ before autoclaving at $121 \mathrm{C}^{\circ}$ and $1.1 \mathrm{~kg} / \mathrm{cm}^{2}$ for $20 \mathrm{~min}$.

Individual plantlets at length 7-9 $\mathrm{cm}$ with 2-3 leaves were cultured in large tubes $(28 \times 250 \mathrm{~mm})$ each tube contained $25 \mathrm{ml}$ liquid MS basal medium in addition to $0.1 \mathrm{NAA} \mathrm{mg} / \mathrm{L}$ and sucrose was added at varying concentrations, all tubes capped with aluminum foil caps .

\section{Effect of sucrose and MS-salt strength concentrations:}

Different sucrose concentration (0.0, 10 and $20 \mathrm{~g} / \mathrm{L}$ ), different MS-salt strength $(1 / 2,1 / 4,1 / 8,1 / 16 \mathrm{MS})$ and different combinations between them for 
plantlets of date palm dry cultivars (Bartamuda and Sakkoty). Each treatment included 3 replicates and each replicate involved 15 plantlets.

\section{Statistical analysis}

The experiments were carried out using completely randomized design and treatment was replicated three times. The results were analyzed using analysis of variance and the means compared using L.S.D test at 5\% according to Steel and Torrie (1980).

\section{RESULTS}

Effect of sucrose and MS-salt strength concentrations on plant height of date palm cultivars:

Data in Table 1 showed that sucrose concentrations affect significantly on plant height. The highest significant mean values were observed by using medium without sucrose and that of adding $10 \mathrm{~g} / \mathrm{L}$ sucrose without difference in between (18.02 and $17.89 \mathrm{~cm} /$ plant, respectively).

According to the effect of MS-salt strength data revealed that using $1 / 2$ MS produced the highest significant mean value $(17.89 \mathrm{~cm} /$ plant $)$, while no significant differences were observed between other treatments.

Data also showed that, interaction between sucrose and MS-salt strength indicated that $1 / 2 \mathrm{MS}$ without sucrose gave the highest mean value $(19.30 \mathrm{~cm} /$ plant) while using $1 / 4$ and $1 / 8 \mathrm{MS}+10 \mathrm{~g} / \mathrm{L}$ sucrose produced the lowest mean values $(15.08$ and $15.00 \mathrm{~cm} /$ plant respectively). Other treatments produced intermediate values between the highest and the lowest values.

Data about cultivars showed that plantlet of Sakkoty cv. was superior on producing plant height $(18.29 \mathrm{~cm} /$ plant $)$ than plantlet of Bartamuda cultivar $(16.18 \mathrm{~cm} /$ plant$)$.

\section{Effect of sucrose and MS-salt strength concentrations on leaves number of date plam cultivars:}

Date tabulated in Table 2 revealed that number of leaves was not affected significantly by sucrose concentrations. Regarding the effect of MS-salt strength data showed that high values of number of leaves resulted from 1/8 and 1/16 MS without significant difference between them (3.53 and 3.35, respectively). Also, no significant differences between other treatments. 
Table 1. Effect of different MS-salt strength and sucrose concentrations on plant height $(\mathrm{cm})$ of date palm cvs. Bartamuda and Sakkoty after 6 weeks from culture.

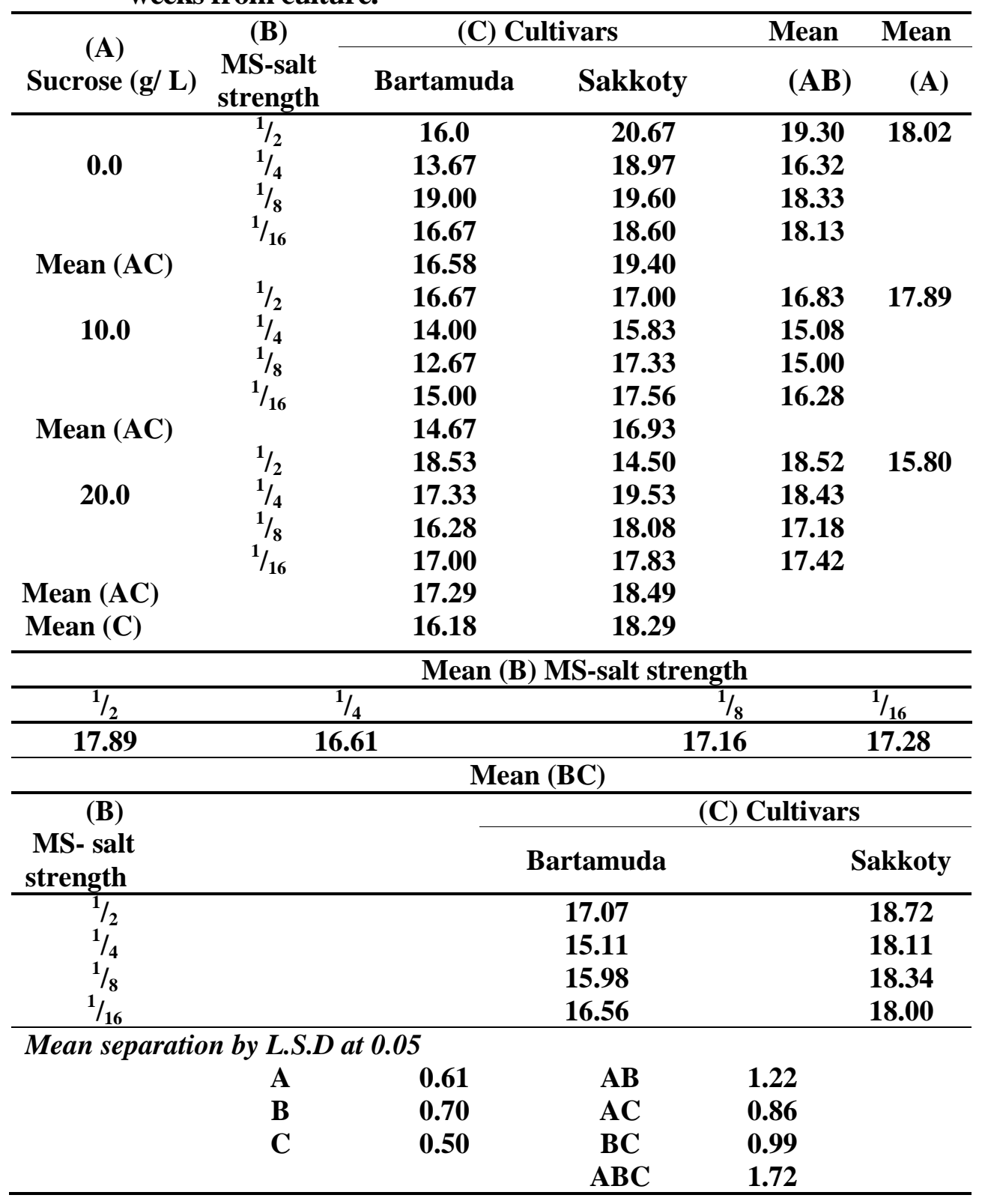


Table 2. Effect of different MS-salt strength and sucrose concentrations on leave number of date palm cvs. Bartamuda and Sakkoty after 6 weeks from culture.

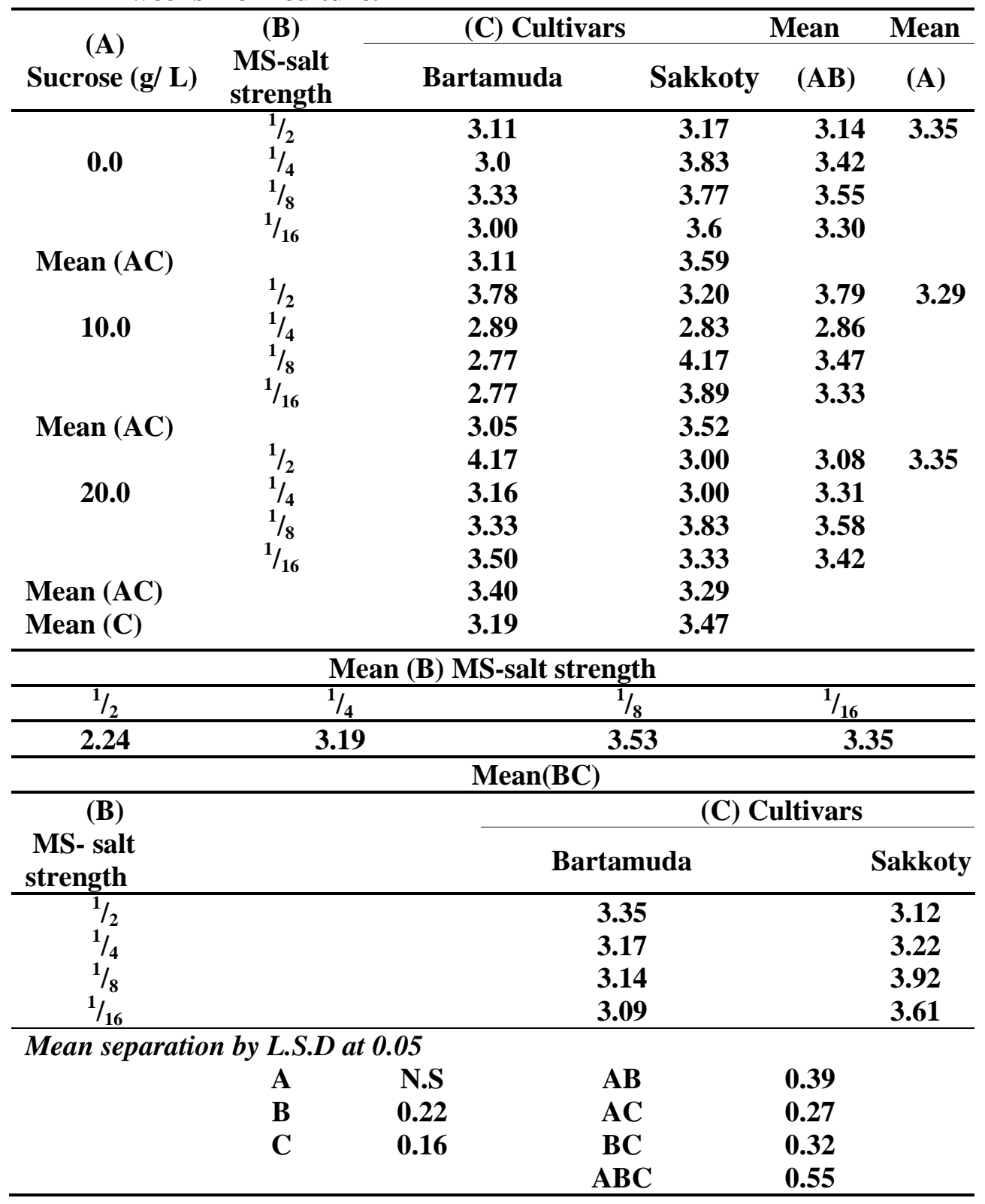

As for the interaction between sucrose and MS-salt strength, data revealed that $1 / 4 \mathrm{MS}$ without or with sucrose at 10 or $20 \mathrm{~g} / \mathrm{L}$ gave the highest mean value of leaves number without difference between them (3.47 and 
$3.42,3.31$, respectively) .On the other hand, the lowest number of leaves was obtained with $1 / 8 \mathrm{MS}+10 \mathrm{~g} / \mathrm{L}$ sucrose (2.86).

Also, data indicated that Sakkoty cv. was produced the highest significant mean value of leave number (3.47) compared with Bartamuda cv. (3.19).

\section{Effect of sucrose and MS-salt strength concentrations on root number of date palm cultivars:}

Data tabulated in Table (3) indicated that the highest significant number of roots (3.28 and 3.09) was recorded by sucrose at 10 and $20 \mathrm{~g} / \mathrm{L}$, respectively, without significant differences between them.

The results concerning the specific effect of the MS-strength indicated that, no significant difference were observed between 1/2,1/4 and 1/16 MS on highest mean values of root number ( $3.44,3.29$ and 3.21, respectively) while 1/8 MS produced the lowest mean value of root number (2.57) .

The interaction between sucrose and MS- salt strength data and fig. (A) showed that $1 / 2$ and $1 / 4$ MS without sucrose gave the highest mean values (3.75, 3.47 ), while $1 / 8 \mathrm{MS}+20 \mathrm{~g} / \mathrm{L}$ sucrose gave the lowest mean value of root number (2.06).

Considering the effect of cultivars regardless sucrose and MS-salt strength concentrations data indicated that Sakkoty cv. was spurious for producing root number (3.46) than Bartamuda cv.(2.79).

Effect of sucrose concentrations and MS-salt strength on root length of date palm cultivars:

Date in Table (4) indicated that no distinctive difference was observed among 0.0, 10 and $20 \mathrm{~g} / \mathrm{L}$ sucrose on root length.

As for the effect of MS-salt strength regardless of sucrose concentrations data revealed that the $1 / 16,1 / 8,1 / 4$ MS produced the tallest roots without significant difference between them.

Interaction between sucrose and MS-salt strength indicated that 1/4 MS + 0.0 sucrose gave the highest value (4.67). On the contrary, $1 / 4 \mathrm{MS}+10 \mathrm{~g} / \mathrm{L}$ sucrose gave the lowest value (2.86).

Plantlet of Sakkoty cv. produced the highest significant value of root length compared with plantlet of Bartamuda cv. 
Table 3. Effect of different MS-salt strength and sucrose concentrations on root number of date palm cvs. Bartamuda and Sakkoty after 6 weeks from culture.

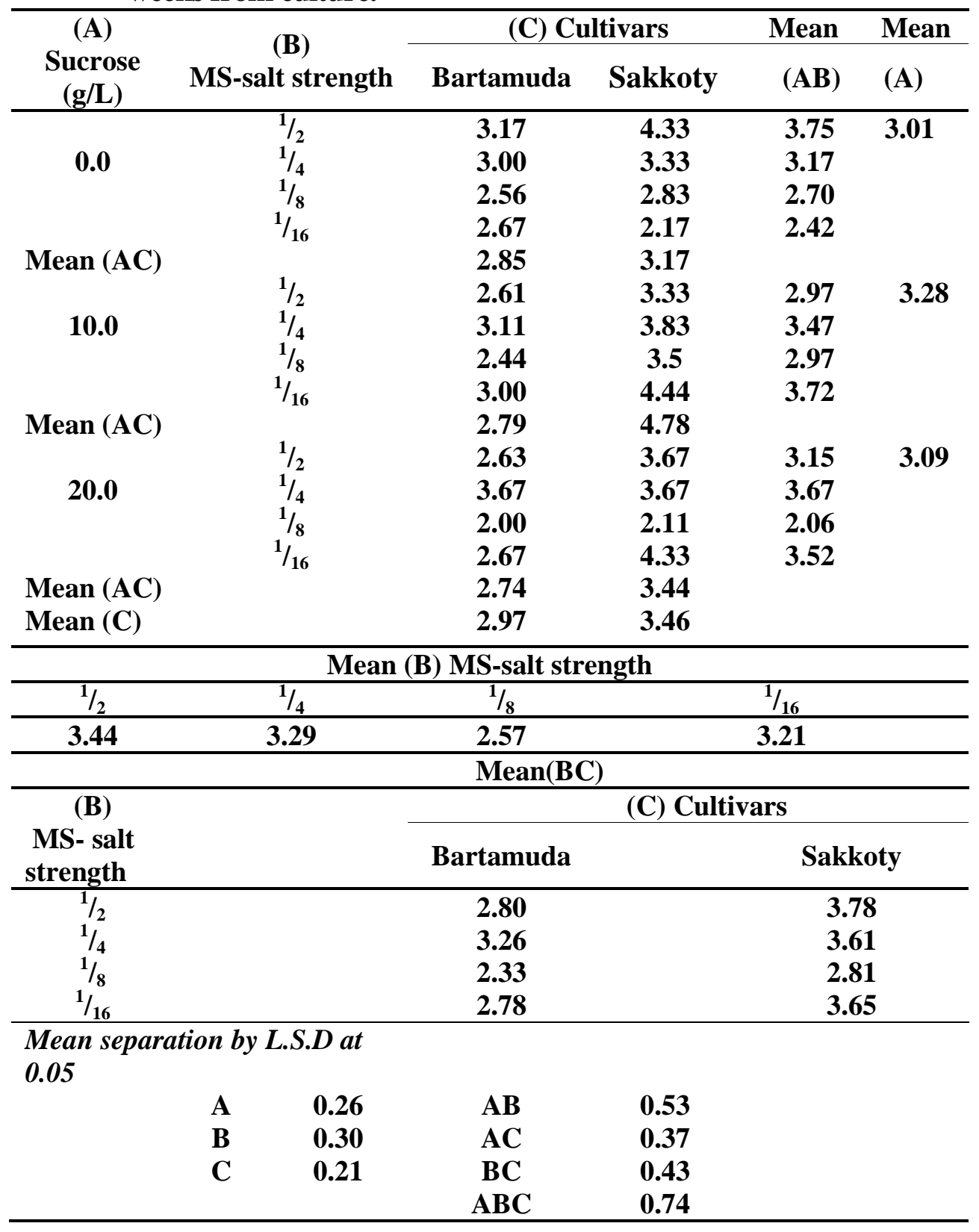




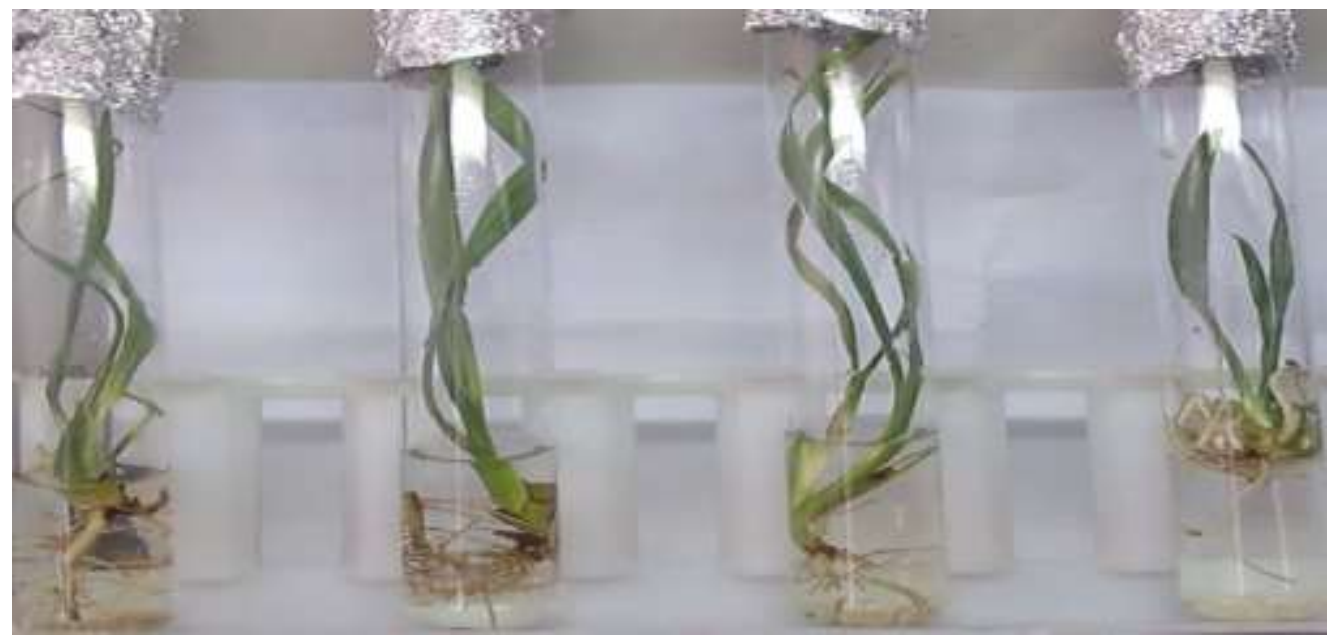

Sakkoty cv.

2 2 3 4

Figure (A). Effect of different MS-salt strength and sucrose concentrations on rooting stage of Phoenix dactylifera cvs. Sakkoty and Bartamuda.

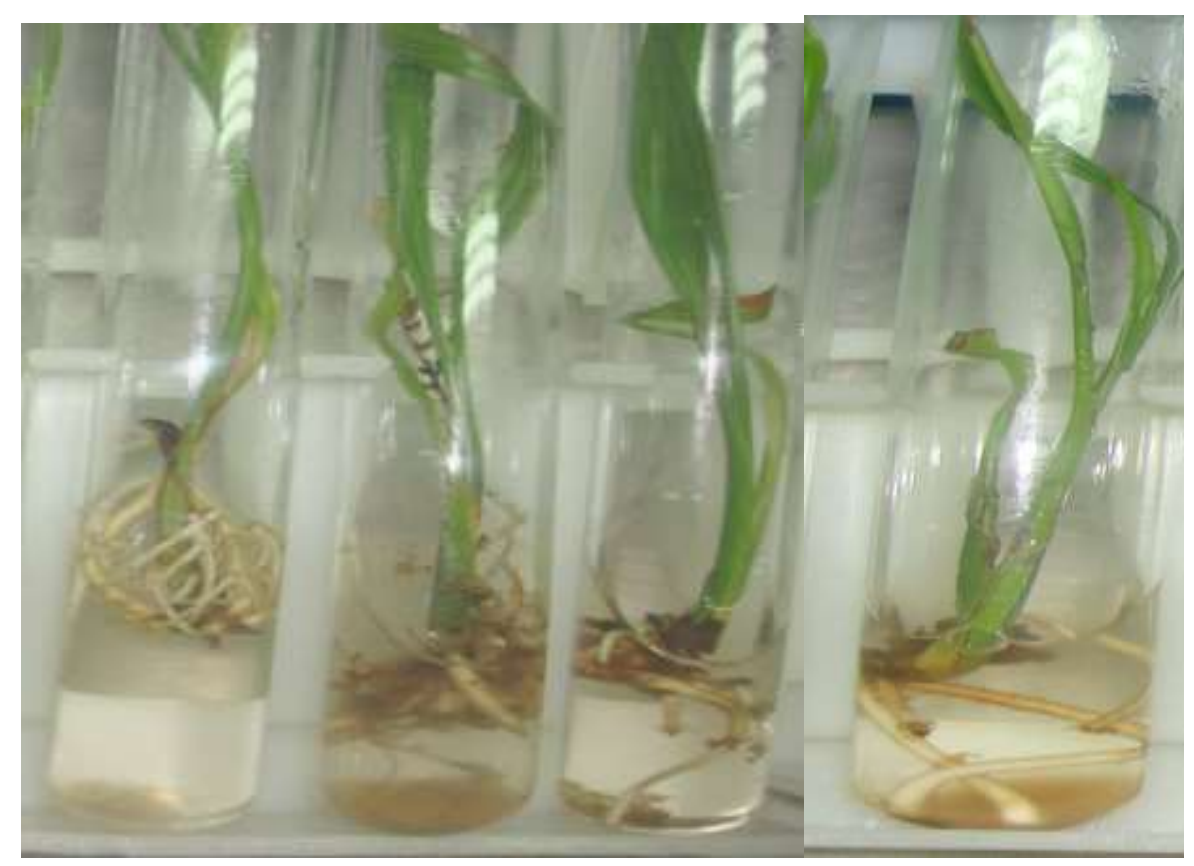

\section{Bartamuda cv.}

(1) $=1 / 2 \mathrm{MS}+20 \mathrm{~g} / \mathrm{L}$ sucrose

(2) $=1 / 4 \mathrm{MS}+,,, \quad, "$

(3) $=1 / 8 \mathrm{MS}+$

(4) = 1/16 MS +, , , , , 
Table 4. Effect of different MS-salt strength and sucrose concentrations on root length $(\mathrm{cm})$ of date palm cvs. Bartamuda and Sakkoty after 6 weeks from culture.

\begin{tabular}{|c|c|c|c|c|c|}
\hline \multirow{2}{*}{$\begin{array}{c}\text { (A) } \\
\text { Sucrose } \\
\text { (g/L) }\end{array}$} & \multirow{2}{*}{$\begin{array}{c}\text { (B) } \\
\text { MS-salt strength }\end{array}$} & \multicolumn{2}{|c|}{ (C) Cultivars } & \multirow{2}{*}{$\begin{array}{l}\text { Mean } \\
\text { (AB) }\end{array}$} & \multirow{2}{*}{$\begin{array}{c}\text { Mean } \\
\text { (A) }\end{array}$} \\
\hline & & Bartamuda & Sakkoty & & \\
\hline \multirow{4}{*}{$\mathbf{0 . 0}$} & $1 / 2$ & 3.11 & 3.08 & 3.75 & 4.71 \\
\hline & $1 / 4$ & 2.92 & 4.50 & 3.17 & \\
\hline & $1 / 8$ & 2.67 & 5.77 & 2.70 & \\
\hline & $1 / 16$ & 3.50 & 4.17 & 2.42 & \\
\hline \multirow[t]{2}{*}{ Mean (AC) } & & 3.05 & 4.38 & & \\
\hline & $1 / 2$ & 3.71 & 3.63 & 2.97 & 3.68 \\
\hline \multirow{3}{*}{10.0} & $1 / 4$ & 2.56 & 3.17 & 3.47 & \\
\hline & $1 / 8$ & 3.50 & 4.33 & 2.97 & \\
\hline & $1 / 16$ & 4.23 & 4.30 & 3.72 & \\
\hline \multirow[t]{2}{*}{ Mean (AC) } & & 3.50 & 3.86 & & \\
\hline & $1 / 2$ & 3.83 & 3.86 & 3.15 & 3.74 \\
\hline \multirow[t]{3}{*}{20.0} & $1 / 4$ & 3.33 & 3.50 & 3.67 & \\
\hline & $1 / 8$ & 2.08 & 6.00 & 2.06 & \\
\hline & $1 / 16$ & 2.83 & 4.33 & 3.50 & \\
\hline Mean (AC) & & 3.2 & 4.47 & & \\
\hline $\operatorname{Mean}(\mathrm{C})$ & & 3.19 & 4.23 & & \\
\hline \multicolumn{6}{|c|}{ Mean (B) MS-salt strength } \\
\hline $1 / 2$ & $1 / 4$ & $1 / 8$ & \multicolumn{3}{|c|}{$1 / 16$} \\
\hline 3.48 & 3.75 & 3.78 & \multicolumn{3}{|c|}{3.84} \\
\hline \multicolumn{6}{|c|}{$\operatorname{Mean}(\mathrm{BC})$} \\
\hline (B) & & \multicolumn{4}{|c|}{ (C) Cultivars } \\
\hline $\begin{array}{l}\text { MS- salt } \\
\text { strength }\end{array}$ & & \multicolumn{2}{|l|}{ Bartamuda } & \multicolumn{2}{|c|}{ Sakkoty } \\
\hline $1 / 2$ & & \multicolumn{2}{|l|}{3.55} & \multicolumn{2}{|c|}{3.40} \\
\hline $1 / 4$ & & \multicolumn{2}{|l|}{2.94} & \multicolumn{2}{|c|}{4.56} \\
\hline $1 / 8$ & & \multicolumn{2}{|l|}{2.75} & \multicolumn{2}{|c|}{4.81} \\
\hline $1 / 16$ & & \multicolumn{2}{|l|}{3.52} & \multicolumn{2}{|c|}{4.17} \\
\hline \multicolumn{6}{|c|}{ Mean separation by L.S.D at 0.05} \\
\hline & A N.S & $\mathbf{A B}$ & 0.46 & & \\
\hline & 0.27 & $\mathbf{A C}$ & 0.33 & & \\
\hline & 0.19 & BC & 0.38 & & \\
\hline & & $\mathbf{A B C}$ & 0.65 & & \\
\hline
\end{tabular}


The effect of sucrose and MS-salt strength concentrations on number of secondary roots of date palm cultivars:

Our observation in Table (5) recorded that The highest significant mean value of average of number of secondary roots (22.69) was produced when using media without sucrose, followed by $10 \mathrm{~g} / \mathrm{L}$ sucrose (17.57), while the lowest significant value (17.57) of sucrose at $10 \mathrm{~g} / \mathrm{L}$.

Data clearly revealed that MS-salt strength had a significant effect of average of number of secondary roots. Using 1/4 MS gave the highest mean value (19.85) of number

of secondary roots. Data also cleared that $1 / 2 \mathrm{MS}$ resulted in the lowest significant mean value (15.72).

The interaction between sucrose concentrations and MS-salt strength, data in Table (5) indicated that $1 / 16 \mathrm{MS}$ without sucrose gave the highest significant average secondary roots number (25.94) followed 1/4 MS without sucrose (24.67). On the other hand, the lowest value (8.88) was obtained with 1/16 MS + $20 \mathrm{~g} / \mathrm{L}$ sucrose.

Observation about the effect of cultivars showed that Bartamuda cv. gave the high significant mean value (20.29) compared with Sakkoty cv. (15.95).

\section{The effect of sucrose and MS-salt strength concentrations on secondary root length of date palm cultivars:}

Data in Table (6) showed that sucrose concentrations affect significantly on average of secondary roots length. Media without sucrose gave the highest significant secondary root length (1.02). Also, the magnitude of sucrose at $20 \mathrm{~g} /$ $\mathrm{L}$ gave the lowest mean value (0.79).

The specific effect of MS-salt strength regardless of sucrose revealed that 1/4 MS gave the highest significant mean value (1.04), followed by $1 / 16$ and $1 / 8$ MS (0.90 and 0.86 , respectively) without significant difference in between. While $1 / 2$ MS gave the lowest significant mean value (0.72).

The interaction between sucrose and MS-salt strength, data clearly showed that 1/16 and 1/4 MS without sucrose produced the highest significant mean values (1.32 and 1.24, respectively) without difference between them. On the other hand, using high concentration of sucrose $(20 \mathrm{~g} / \mathrm{L})$ with $1 / 2 \mathrm{MS}$ produced the lowest mean value (0.64).

Observation about cultivars, data indicated that plantlet of Bartamuda cv. was significantly higher (0.95) than Sakkoty cv. (0.81). 
Table 5. Effect of different MS-salt strength and sucrose concentrations on number of secondary roots of date palm cvs. Bartamuda and Sakkoty after 6 weeks from culture.

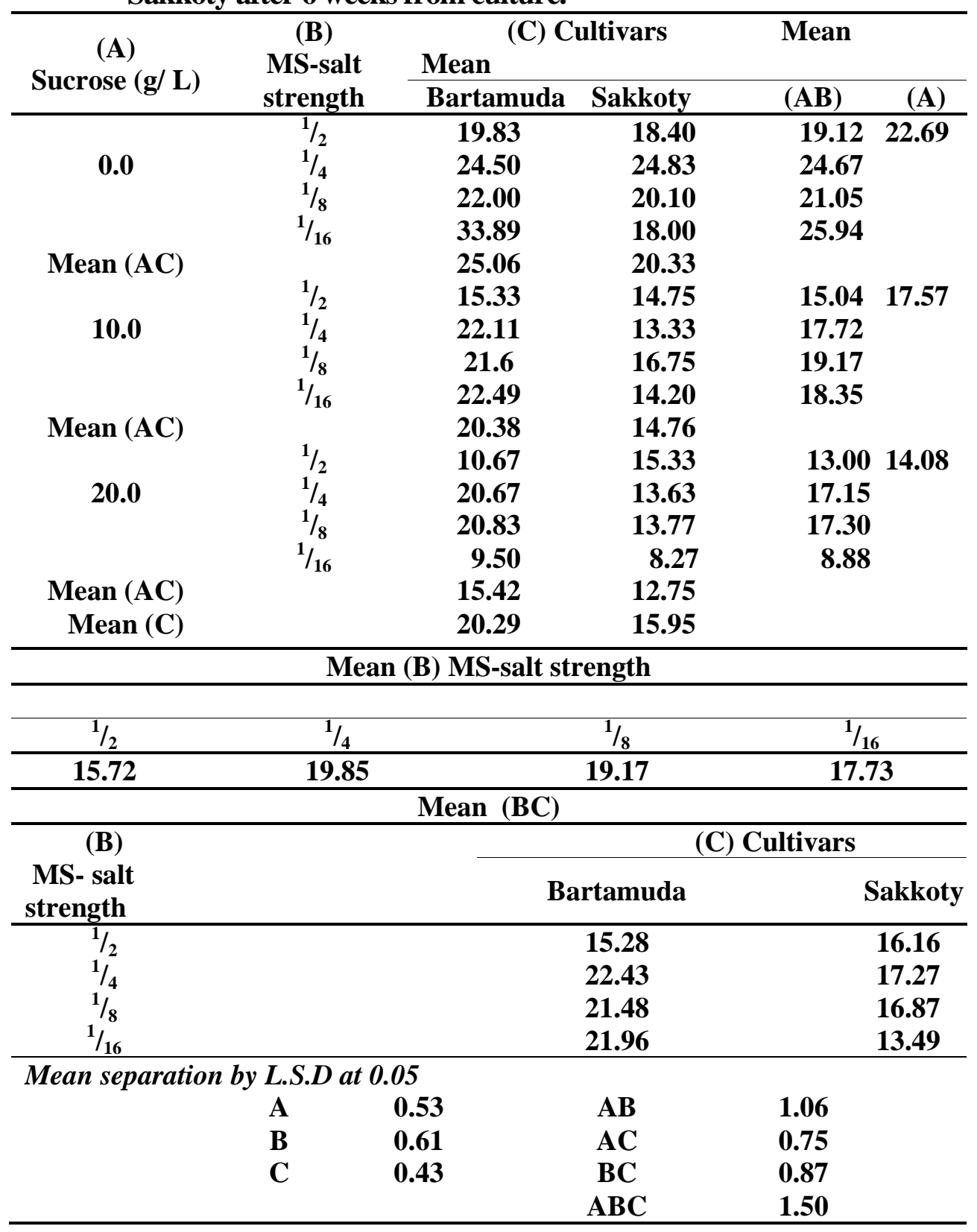


Table 6. Effect of different MS-salt strength and sucrose concentrations on secondary root length $(\mathrm{cm})$ of date palm cvs. Bartamuda and Sakkoty after 6 weeks from culture.

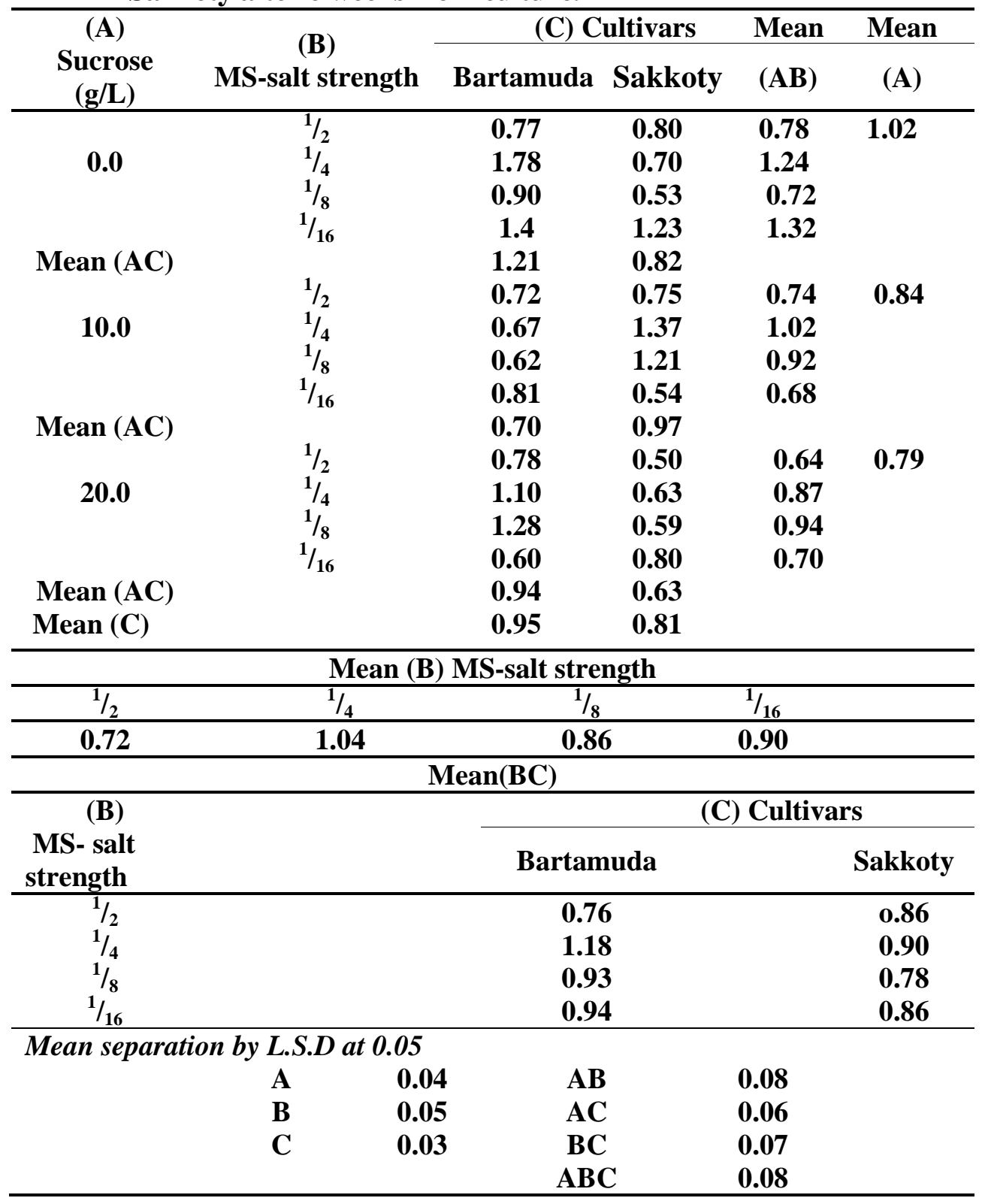




\section{DISCUSSION}

\section{Effect of sucrose concentrations regardless of MS-salt strength:}

To negate the need for plants to be photosynthetically active, or even photosynthetically competent under artificial lighting, sucrose is added to the medium as a carbohydrate source (John et al., 2003). The role of sucrose in rooting is more closely linked to the energy supplies than to its osmotic properties in rose shoots (Hyndman et al., 1982). Photosynthesis is inhibited when sucrose levels increase from 3\% to $6 \%$ resulting in high levels of starch and sucrose in plantlets at the end of the in vitro period (Huylenbroeck and Debergh, 1996). Plantlets can grow in vitro in a sugar - free culture medium provided the environment is conductive to photosynthesis (Kozai, 1991).

Similarly with sugar-free media, in vitro carbon dioxide enrichment in association with relative humidity reduction promoted growth, including rooting, of transplants of red raspberry (Deng and Donnelly, 1993). Potato plantlets cultured on sucrose-free medium with high light and carbon dioxide levels were vigorous with good roots so that no particular rooting or acclimatization processes were required following transfer to the greenhouse (Kozai et al., 1988). Al-Dawayati (2000) who reported that adventitious roots of date palm plantlets formation and adventitious roots length were decreased with increasing sucrose concentration in culture media.

\section{Effect of MS-salt strength regardless of sucrose concentrations:}

Reduction of the concentration of MS-salt strength to 3/4 of the original formulation stimulated both root formation and plant length of date palm plantlets (Abo-El-Soaud, 1999). Khosh and Sink (1982) found that among the MS-salt concentration used in the study on Rose hybrid, 1/2 strength was found to be more effective than either full or 1/4 strengths.

Scotti and Pais (1990) observed that the highest percentage of rooting and vigorous dwarf rose cultivars " Rossamini" plantlets, as well as the highest number of roots per plant were obtained in half strength MS. Drew (1987) showed that a reduced mineral concentration on the papaya rooting medium increased root initiation. Zein El Din (2005) found that using 1/4 MS-salt strength led to a significant increase in roots number and length in data palm cultivars.

As for the interaction between sucrose and MS-salt strength concentrations:

Growth of carnation plantlets under high light levels was greater on a sugar-free medium using nutrient components widely used in hydroponic culture than either on a sugar-free medium with 1/2 Murashige and Skoog (MS) (Murashige and Skoog, 1962) or sugar containing hydro-ponic or 1/2 MS media (Kozai et al., 1988) . 
Takayama and Misawa (1981) on Begonia hiemalis, mentioned that root development was superiors in 1/4 strength MS medium. Schum and Bichler (1986) on Gerbera jamsonii, found that, increasing the concentration of macroelements of MS medium had negative effects on root growth. Liu et al (1994) reported that root growth of Dendranthema grandiflora was best on $1 / 2$ MS medium supplemented with $0.1 \mathrm{mg} / \mathrm{L}$ NAA.

On the other hand, Ibrahim et al. (1999) mentioned that the combined effect between sucrose concentrations and MS salt strength indicated that the media to stimulate the growth and development of adventitious roots of date palm plantlets which contained the $3 / 4 \mathrm{MS}$ salt strength $+50 \mathrm{~g} / \mathrm{L}$.

Conclusively, The combined effect between sucrose concentration and MS salt strength indicated that the best medium to stimulate the growth and development of adventitious roots of date palm plantlets which contained the 1/4 MS salt strength supplemented with $20 \mathrm{~g} / \mathrm{L}$ sucrose. Sakkoty cv. produced the highest significant value of plant height, leave number, root number and root length compared with Bartamuda cv.

\section{REFRENCE}

Al-Dawayati, M. M. (2000). Physiological studies on date palm micropropagation, M. Sc. Thesis, Department of Penology, Faculty of Agriculture, Cairo University, Egypt.

Abo-El-Soaud, A.A. (1999). Studies on date palm propagation through tissue culture, M. Sc. Thesis, Department of Pomology, Faculty of Agriculture, Cairo University, Egypt.

DE Fossard, R.A., (1976). Tissue culture for plant propagators. Department Continuing Ed., University New England Armidale, Australia. 1-409.

Deng, R. and D.J Donnelly (1993). In vitro hardening of red raspberry through $\mathrm{CO}_{2}$ enrichment and relative humidity reduction on sugar-free medium. Can. Journal Plant Science, 73:1105-1113.

Drew, R.A. (1987). The effects of medium composition and cultural conditions on in vitro root initiation and growth of papaya (Carica papaya L.). Journal of Horticultural Science, 62:551-6.

El Hadrami, I.; M. El Bellaj; A. El Idrissi; F. J Aiti; S, El jaafari and F. Daayf (1998). Biotechnologies vegetates et amelioration du palmier dattier (Phoenix dactylifera L.). privot de lagriculture oasienne marocaine. Cahiers Agriculture, 7: 463-468.

Haissig, B.E. (1984): carbohydrates accumulation and partitioning in (prnus banksions) seedlings and seedlings cuttings. Physiology Plant, 6: 13-15. 
Huylenbroeck, J.M. van and P.C. Debergh (1996): Impact of sugar concentration in vitro on photosynthesis and carbon metabolism during ex vitro acclimatization of Spathiphyllum plantlets. Physiology Plant, 96:298-304.

Hyndman, S.E; P.M. Hasegawa and R.A. Bressan (1982). The role of sucrose and nitrogen in adventitious root formation on cultured rose shoots. Plant Cell, Tissue and Organ Culture, 1:229-238.

Ibrahim, A.I; A.A.Abo-El-soaud; N.R. El-Sherbeny and E.I.Baker (1999). Effect nutrient media on the growth and development of date palm grown in vitro and ex vitro. $1^{\text {st }}$ International Conference, in Egypt, on plant tissue culture and its applicant. At 12-14 September, University of Zagazig, Egypt, 209-217.

John, F.S; K.B.Garry and E.R. Morgan (2003): Acclimatizing tissue culture plants.Reducing the shock. Combined Proceedings International Plant Propagators' Society, 53:85-90.

Khosh-Khui, M. and K.C Sink (1982): Rooting enhancement of Rosa hybrida for tissue culture propagation. Host Science, 17:371-376.

Kozai, T. (1991). Autotrophic micropropagation, 313-343 in: Y.P.S Bajaj (ed) Biotechnology in agriculture and forestry 17: High-tech and micropropagation Springer Verlag, New Yourk.

Kozai, T., C.Kobuta, and I. Watanabe. (1988). Effect of basal medium composition on the growth of carnation plantlets in auto- and mixotrophic tissue culture. Acta Hort., 230: 159-166.

Liu, H.W; H.Zhang; Z.F.Ma and Y.Liang (1994). Fast breeding of groundcover Chrysanthemum. Journal of Northeast, Forestry University, 22:1.31 -35.

Murashige, T. and F. Skoog (1962): A revised medium for rapid growth and bio assays with tobacco tissue cultures. Physiology Plant, 15:473-497.

Nemeth, G. (1986): Induction of Rooting Chapter IV. Biotechnology in Agriculture and Forestry, Vol. 1: Trees 1 (ed.) by Y.P.S. Bajaj. SpringerVerlag Berlin Heidelberg.

Nwankwo, B.A. and Krikorian, A.D. (1983). Morphogenetic potential of embryo and seedling-derived callus of Elaeis guineensis jacq. var. Pisifera Becc. Ann. Bot., 51:65-76

Schum, A. and I.Bichler (1986). Rooting and quality of Gerbera in vitro. Effects of various nutrient ingredients. Deustscher - Gartenbau, 40(4): 140 144.

Scotti, C. P. and M.S. Pais (1990). Mass propagation the dwarf rose cultivar. Rosamini. Hort Science, 43: 321-330. 
Steel; R.G. and J. H. Torrie (1980). Principles and Procedures of Statistics. A Biometrical Approach Mc Grow- Hill book Company, New Yourk, 469517.

Takayama, S. and M. Misawa (1981): Mass propagation of Begonia hiemalis plantlets by shake culture. Plant and Cell Physiology, 22: 3.461-467.

Tisserat, B. (1984): Propagation of date palm by shoot tip cultures. Hort. Science, 19:230-231.

Zein El Din, A.F. (2005): Physiological studies on vegetative propagation of some date palm cultivars us if the tissue culture technique. M. Sc. Thesis, Department of Agricultural Botany, Faculty of Agriculture, Ain Shams University, Egypt.

\section{تأثير تركيز السكروز وقوى الأملاح على تطور نباتات نخيل البلح

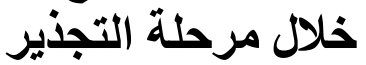

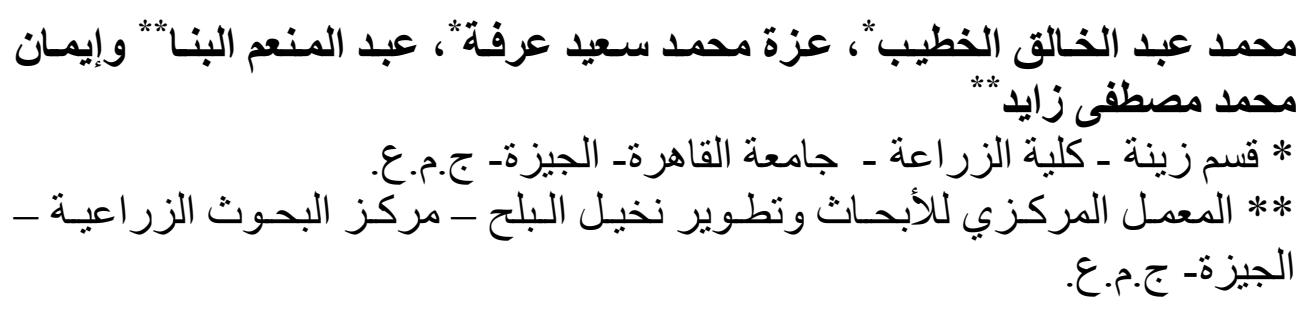

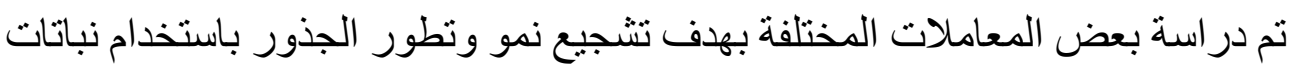

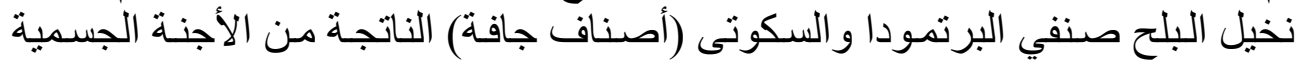

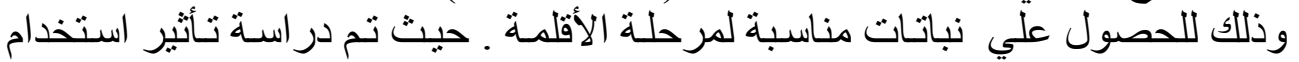

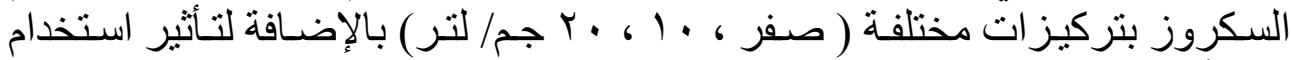

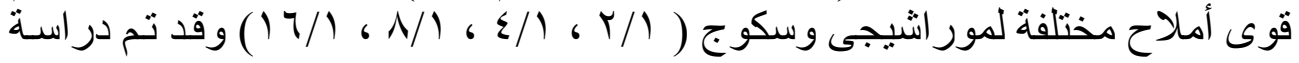

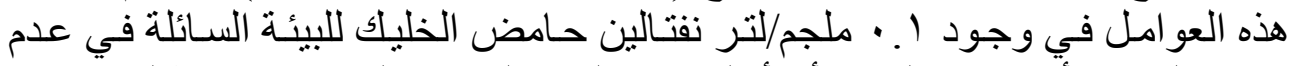

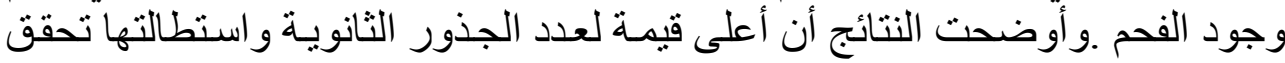

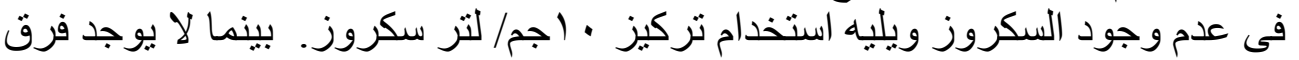

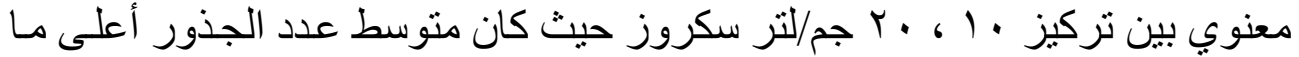

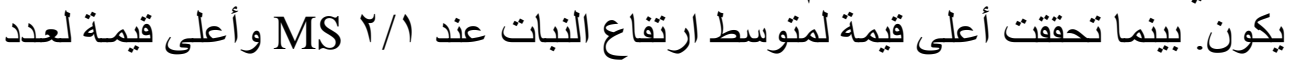

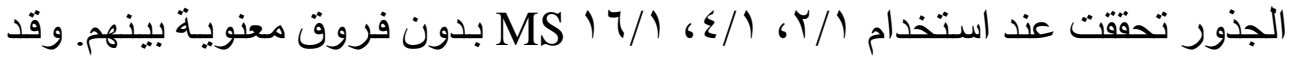

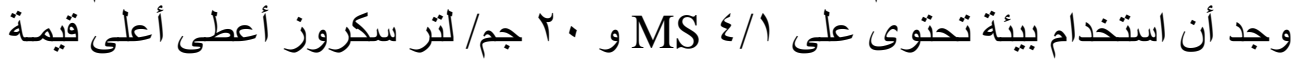

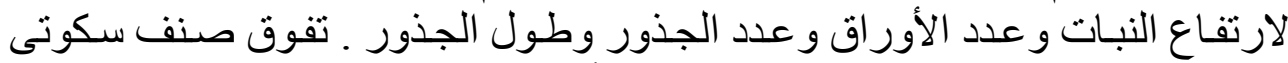
على صنف برتمودا في ارتفاع النبات و عدد الأوراق و عدد الجذور وطول وطول الجذور. 